\title{
Discrimination of hydrogen-bonded complexes with axial chirality
}

\author{
Ibon Alkorta ${ }^{\mathrm{a})}$ and José Elguero \\ Instituto de Química Médica (C.S.I.C.), Juan de la Cierva, 3, E-28006 Madrid, Spain
}

(Received 11 June 2002; accepted 12 July 2002)

\begin{abstract}
The chiral self-discrimination of twelve molecules showing axial chirality has been studied. They included peroxides, hydrazines, carboxylic acids, amides, and allenes. The homo and heterochiral dimers of the selected compounds, that present two hydrogen bonds, have been studied by means of density functional theory (B3LYP/6-31+ $\mathrm{G}^{* *}$ ) and $a b$ initio (MP2/6-31+ $\mathrm{G}^{* *}$ and MP2/6-311 $\left.+\mathrm{G}^{* *}\right)$ methods. The energetic differences found for the complexes of each compound have been rationalized based on their electron density maps and the natural bond orbital analysis. In some cases, intermolecular oxygen-oxygen interactions have been found and interpreted as additional stabilizing contacts. (C) 2002 American Institute of Physics. [DOI: 10.1063/1.1504710]
\end{abstract}

\section{INTRODUCTION}

The chiral discrimination through hydrogen-bonded complexes is of paramount importance in biological processes where only one enantiomer is present as building block of the proteins (L-aminoacids) and nucleic acids (Dsugars). In addition, such discrimination can be found in liquid chromatography separation of enantiomers, the application of chiral additives in nuclear magnetic resonance (NMR), and some crystallization of racemix mixtures.

Wynberg and Feringa ${ }^{1}$ proposed in 1976 that the different reactivity of pure enantiomeric mixtures and racemic ones based on the difference of what they called the "enantiomeric recognition" effect in the first case and "antipodal interaction" in the latter. In the same year, Craig and Mellor ${ }^{2}$ review the energetic sources of the chiral discrimination in intermolecular interactions and introduced the term chirodiastaltic to define them.

Only a few articles have explored the study of the chiral discrimination due to hydrogen bond complexation using $a b$ initio methods. Leutwyler and co-workers ${ }^{3}$ studied the interaction of the two isomers of $\mathrm{HOOH}$ and chiral derivatives of oxirane using MP2 and B3LYP computational methods. The largest chirodiastaltic energy found was $0.46 \mathrm{kcal} / \mathrm{mol}$. In addition, Alkorta and Elguero ${ }^{4}$ studied the selfdiscrimination of a series of $\beta$-aminoalcohols. In all the cases studied, the most stable dimer was the heterochiral one $(R S$ or $S R$ ) up to $1.60 \mathrm{kcal} / \mathrm{mol}$. However, when the solvent effect was considered the stability of several of the complexes was reversed in favor of the homochiral one $(R R$ or $S S)$.

In the case of compounds with axial chirality, the configuration of the two different enantiomers are denoted with the stereodescriptors $R a$ and $S a$ (or by $P$, plus, and $M$, minus). ${ }^{5}$ This kind of chirality is characteristic of allenes and biphenyl derivatives. In fact, a recent work by Zavada and co-workers ${ }^{6}$ shows the self-assembling properties in solid

\footnotetext{
a) Author to whom correspondence should be addressed. Electronic mail: ibon@iqm.csic.es; Fax: +34-91-564 4853.
}

state of enantiopure and racemic biaryl systems by HB complexation.

In this article, the homo- and heterochiral selfassociation of 12 compounds that show axial chirality have been studied using density functional theory (DFT) (B3LYP/6-31+ $\mathrm{G}^{* *}$ ) and ab initio (MP2/6-31+ $\mathrm{G}^{* *}$ and MP2/6-311 $\left.+\mathrm{G}^{* *}\right)$ methods. The atoms in molecules (AIM) and natural bond orbital (NBO) methodologies have been used to characterize the electron density and the orbital interactions, respectively. The presence of intermolecular bond critical points, confirmed by the NBO analysis, has been used to explain the relative stability of the complexes.

\section{METHODS}

A number of compounds with axial chirality have been selected for this work (Fig. 1). The selection of the systems studied (Fig. 1) has been carried out based on their small size and chemical variety. Thus, a set of three derivatives of hydrogen peroxide (1-3), three of hydrazine (4-6), three of performic acid (7-9), one of $N$-hydroxyformamide (10), and two allenes (11) has been considered.

In all the cases, a HB donor center with a HB acceptor one are present in each molecule. Thus, only those configurations with a double HB interaction have been considered where each molecule acts as HB donor and acceptor simultaneously. In general, the homochiral and heterochiral complexes adopt a $C_{2}$ and $C_{i}$ symmetry, respectively.

The geometry of the monomers and complexes has been optimized at the B3LYP/6-31+G** (Refs. 7, 8) computational level with the GAUSSIAN 98 program. ${ }^{9}$ The minimum nature of the complexes has been confirmed by frequency calculations. In addition, a further optimization has been carried out in all the systems at the MP2/6-31+G** and MP2/6-311 $++\mathrm{G}^{* *}$ levels ${ }^{10}$ within the frozen core (FC) approximation.

The interaction energy has been obtained as the difference of the energy of the dimers and two times those of the corresponding monomers. The interaction energy has been corrected from the inherent basis sets superposition error (BSSE) using the full counterpoise method of Boys and 

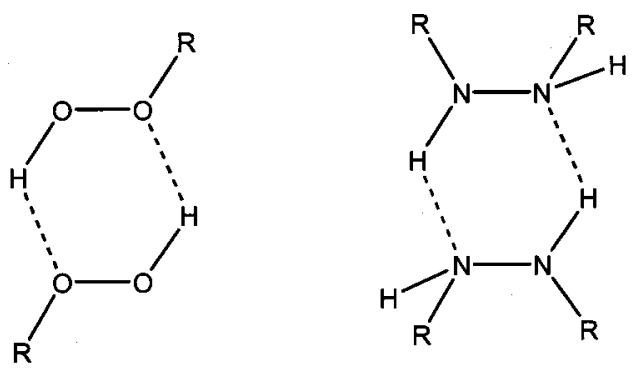

$\begin{array}{cc}\underline{\mathrm{R}} & \\ \mathrm{H} & \mathbf{1} \\ \mathrm{CH}_{3} & \mathbf{2} \\ \mathrm{CF}_{3} & \mathbf{3} \\ \mathrm{HCO} & \mathbf{7}\end{array}$

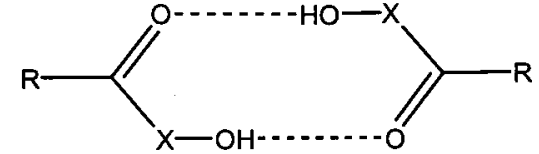

FIG. 1. Schematic representation of the dimer studied.<smiles>O/C=C\C=C/O</smiles>

11

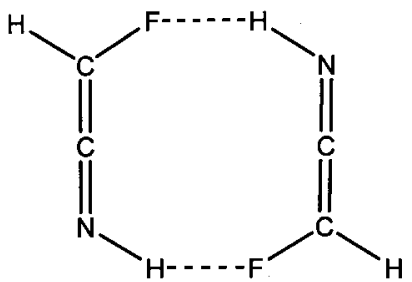

Bernardi ${ }^{11}$ at each calculated level. In addition, the unscaled zero point energies (ZPE) calculated at the B3LYP/6-31+ $\mathrm{G}^{* *}$ level have been taken into account to provide a corrected interaction energies, $E_{I(\mathrm{CORR})}$,

$$
\begin{aligned}
& E_{I}=E_{I}=E_{A B}-E_{A}^{A}-E_{B}^{B}, \\
& \mathrm{BSSE}=\left(E_{A^{\prime}}^{A B}-E_{A^{\prime}}^{A}\right)+\left(E_{B^{\prime}}^{A B}-E_{B^{\prime}}^{B}\right), \\
& \mathrm{ZPE}{ }_{(\mathrm{CORR})}=\mathrm{ZPE}_{A B}-\mathrm{ZPE}_{A}^{A}-\mathrm{ZPE}_{B}^{B}, \\
& E_{I(\mathrm{CORR})}=E_{I}+\mathrm{BSSE}+\mathrm{ZPE}_{(\mathrm{CORR})},
\end{aligned}
$$

where $E_{A}^{A}$ represent the energy of the isolated molecule $A$ at the minimum geometry calculated with its basis set and $E_{A^{\prime}}^{A B}$ corresponds to the calculated energy of molecule $A$ with its geometry in the $A B$ complex using the basis function of the complex $A B$.

The electron density has been analyzed using the atoms in molecules (AIM) ${ }^{12}$ methodology and the AIMPAC ${ }^{13}$ and AIM2000 ${ }^{14}$ programs.

The $\mathrm{NBO}^{15}$ methodology allows us to study the bonding-antibonding orbital interactions. The king of interactions has been described to be the responsible of the stabilization in $\mathrm{HB}$ and other complexes. ${ }^{15}$

\section{RESULTS AND DISCUSSION}

Some of the molecules selected present small energy barriers between the two possible enantiomers but they can be used in theoretical calculations as suitable models of larger molecules for which no such detailed calculation can be carried out. In addition, experimental data of hydrazine clusters indicate the present of both enantiomers. ${ }^{16}$

To our knowledge, of the ten compounds considered here, only the cases of one of the hydrogen peroxide dimers $\mathbf{1}$ and both hydrazine dimers $\mathbf{4}$ have been previously studied theoretically. The most stable dimer of $\mathrm{HOOH}$ was found, ${ }^{17,18}$ at the MP2/6-311+G** level, to be the one with $C_{i}$ symmetry which corresponds to the heterochiral dimer. However, the most stable configuration for the homochiral dimer, which corresponds to a $C_{2}$ symmetry, was left unexplored in these studies. The value reported for the $C_{i}$ dimer of $\mathrm{HOOH}$ at the $\mathrm{MP} 2 / 6-311+\mathrm{G}^{* *}$ level $(-9.44 \mathrm{kcal} / \mathrm{mol})$ (Ref. 16) (other authors found $-6.31 \mathrm{kcal} / \mathrm{mol}$ at the MP2 level including the BSSE correction) ${ }^{18}$ is similar to the ones calculated here $[-8.98(-7.72$ with BSSE), $-9.91(-7.16$ with BSSE), and -9.35 (-6.69 with BSSE) $\mathrm{kcal} / \mathrm{mol}$ for the B3LYP/6-31+G**, MP2/6-31+G**, and MP2/6-311 $++\mathrm{G}^{* *}$ calculations, respectively]. In the case of hydrazine 4 both the homochiral and the heterochiral dimers have been calculated, the second one was the most stable by $0.5-0.8 \mathrm{kcal} / \mathrm{mol}\left[\mathrm{MP} 2 / 6-31++\mathrm{G}^{* *} \text { and } \operatorname{CCSD}(\mathrm{T})\right]^{19}$ (see Table I, $0.5-0.7 \mathrm{kcal} / \mathrm{mol})$. This author was not interested in chiral discrimination but IR spectroscopists found that the $\mathrm{Sa} / \mathrm{Ra}$ dimer of hydrazine explain better the experimental observations than the $\mathrm{Sa} / \mathrm{Sa}(\mathrm{Ra} / \mathrm{Ra})$ dimer. $^{16}$

The relative energy and interaction energies of all the complexes studied here are gathered in Table I and the optimized structure of some of them are shown in Fig. 2. In all the cases, the relative energies at the three methods used here are very similar in value and in all cases with the same sign, 
TABLE I. Relative energy $E_{\text {rel }}$, interaction energy $E_{I}$, corrected interaction energy $E_{I(\mathrm{CORR})}$, and relative energy of the monomers within the dimers $E_{\text {rel }}$ (mon.) (kcal/mol).

\begin{tabular}{|c|c|c|c|c|c|c|c|c|c|c|c|c|c|}
\hline \multirow[b]{2}{*}{ Dimer } & & \multicolumn{4}{|c|}{ B3LYP/6-31+ G** } & \multicolumn{4}{|c|}{ MP2/6-31+ G* $^{* *}$} & \multicolumn{4}{|c|}{$\mathrm{MP} 2 / 6-311++\mathrm{G}^{* *}$} \\
\hline & & $E_{\text {rel }}$ & $E_{I}$ & $E_{I(\mathrm{CORR})}$ & $\begin{array}{c}E_{\text {rel }} \\
\text { (mon.) }\end{array}$ & $E_{\text {rel }}$ & $E_{I}$ & $E_{I(\mathrm{CORR})}$ & $\begin{array}{c}E_{\text {rel }} \\
\text { (mon.) }\end{array}$ & $E_{\text {rel }}$ & $E_{I}$ & $E_{I(\mathrm{CORR})}$ & $\begin{array}{c}E_{\text {rel }} \\
\text { (mon.) }\end{array}$ \\
\hline 1 & $R_{a} / S_{a}$ & & -8.98 & -5.35 & & & -9.91 & -4.78 & & & -9.35 & -4.32 & \\
\hline 1 & $R_{a} / R_{a}$ & 0.41 & -8.57 & -5.05 & 0.001 & 0.40 & -9.51 & -4.56 & 0.00 & 0.19 & -9.17 & -4.14 & 0.02 \\
\hline 2 & $R_{a} / S_{a}$ & & -8.87 & -5.55 & & & -11.20 & -5.58 & & & -10.52 & -5.73 & \\
\hline 2 & $R_{a} / R_{a}$ & 0.50 & -8.37 & -5.20 & -0.035 & 0.52 & -10.68 & -5.34 & -0.12 & 0.36 & -10.16 & -5.36 & -0.05 \\
\hline 3 & $R_{a} / S_{a}$ & & -4.39 & -2.18 & & & -7.26 & -2.71 & & & -7.03 & -2.55 & \\
\hline 3 & $R_{a} / R_{a}$ & -0.40 & -4.79 & -2.44 & 0.009 & -0.97 & -8.23 & -3.18 & 0.03 & -1.18 & -8.21 & -2.96 & 0.04 \\
\hline 4 & $R_{a} / S_{a}$ & & -6.52 & -3.80 & & & -7.98 & -3.97 & & & -7.48 & -3.90 & \\
\hline 4 & $R_{a} / R_{a}$ & 0.73 & -5.79 & -3.22 & -0.009 & 0.64 & -7.34 & -3.46 & -0.02 & 0.48 & -7.00 & -3.45 & -0.02 \\
\hline 5 & $R_{a} / S_{a}$ & & -6.09 & -4.28 & & & -9.26 & -5.20 & & & -8.78 & -5.26 & \\
\hline 5 & $R_{a} / R_{a}$ & 0.47 & -5.62 & -3.91 & -0.003 & 0.27 & -8.99 & -4.91 & 0.01 & 0.19 & -8.59 & -5.07 & 0.00 \\
\hline 6 & $R_{a} / S_{a}$ & & -4.14 & -2.27 & & & -9.72 & -4.43 & & & & & \\
\hline 6 & $R_{a} / R_{a}$ & 0.57 & -3.57 & -1.63 & 0.063 & 0.70 & -9.02 & -3.77 & 0.04 & & & & \\
\hline 7 & $R_{a} / S_{a}$ & & -6.08 & -3.94 & & & -7.91 & -3.95 & & & -8.14 & -4.45 & \\
\hline 7 & $R_{a} / R_{a}$ & -2.83 & -8.91 & -6.16 & 0.230 & -3.94 & -11.85 & -6.45 & 0.18 & -3.66 & -11.80 & -6.54 & 0.20 \\
\hline 8 & $R_{a} / S_{a}$ & & -4.99 & -2.93 & & & -8.35 & -3.69 & & & -8.56 & -4.88 & \\
\hline 8 & $R_{a} / R_{a}$ & -2.78 & -7.77 & -5.14 & 0.31 & -3.09 & -11.45 & -5.75 & -0.25 & -3.14 & -11.70 & -6.32 & -0.23 \\
\hline 9 & $R_{a} / S_{a}$ & & -6.19 & -4.27 & & & -9.75 & -5.53 & & & -9.96 & -6.56 & \\
\hline 9 & $R_{a} / R_{a}$ & -2.35 & -8.54 & -5.96 & 0.12 & -2.93 & -12.68 & -6.89 & 0.24 & -2.89 & -12.85 & -7.35 & 0.25 \\
\hline 10 & $R_{a} / S_{a}$ & & -13.80 & -10.89 & & & -15.76 & -10.17 & & & -15.46 & -11.80 & \\
\hline 10 & $R_{a} / R_{a}$ & -2.72 & -16.52 & -13.33 & 0.38 & -2.76 & -18.51 & -12.46 & 0.36 & -2.76 & -18.23 & -12.34 & 0.39 \\
\hline 11 & $R_{a} / S_{a}$ & & -7.05 & -5.38 & & & -10.21 & -6.09 & & & -9.36 & -6.18 & \\
\hline 11 & $R_{a} / R_{a}$ & -0.65 & -7.69 & -5.91 & 0.07 & -0.98 & -11.20 & -6.89 & 0.10 & -1.03 & -10.39 & -6.07 & 0.09 \\
\hline 12 & $R_{a} / S_{a}$ & & -3.57 & -2.27 & & & -7.00 & -3.82 & & & -6.52 & -4.27 & \\
\hline 12 & $R_{a} / R_{a}$ & 0.21 & -3.35 & -2.08 & -0.01 & 0.48 & -6.52 & -3.53 & -0.01 & 0.44 & -6.07 & -3.31 & 0.01 \\
\hline
\end{tabular}

indicating that the same dimer is the most stable with the two methods. In the same way, the values obtained for the $E_{I(\mathrm{CORR})}$ are very similar in both methods used here.

The values of the BSSE and ZPE corrections are important to determinate the final value of the interaction energy. In some cases, the sum of the corrections can be up to $200 \%$ the value of the $E_{I(\mathrm{CORR})}$. However, the correction values are similar for the two dimers considered for each compound not altering significantly the energy differences without the corrections.

The comparison of the energetic results of the three methods used here indicates that the MP2/6-311+ $+\mathrm{G}^{* *}$ ones are more similar to the $\mathrm{MP} 2 / 6-31+\mathrm{G}^{* *}$ than the B3LYP/6-31+ $\mathrm{G}^{* *}$ ones. Even though the latest provides the same trends than the former, the lack of an adequate treatment of dispersive interactions ${ }^{3}$ by the DFT methods should be responsible of the small differences observed.

The interaction energies $E_{I}$ range between -6.5 and $-18.5 \mathrm{kcal} / \mathrm{mol}$ while the corrected $E_{I(\mathrm{CORR})}$ ones are between -2.7 and $-12.5 \mathrm{kcal} / \mathrm{mol}$. The sign of the relative energies indicates the stability of the homo, heterochiral dimers is divided half-and-half. All the complexes of the HOOR and RHNNHR dimers, with the exception of the
$\mathrm{HOOCF}_{3}$ (3), prefer the heterochiral disposition with chirodiastaltic energy differences between 0.4 and $0.7 \mathrm{kcal} / \mathrm{mol}$. The opposite happened for the peracid and $\mathrm{N}$-hydroxyformamide derivatives where the homochiral configuration is more stable by more than $2.0 \mathrm{kcal} / \mathrm{mol}$.

In order to check that the source of the energy difference of the dimers came from the intermolecular interaction, the energy of the isolated monomers within the dimers have been compared. The energetic differences found between monomers account up to $10 \%$ of the relative energy of the dimers and in general with the opposite sign. Thus, the most stable dimers are formed with the less stable monomers.

Additional configurations have been studied in the $\mathrm{HCOOOH}$ compound at the B3LYP/6-31+ $\mathrm{G}^{* *}$ level in analogy of those found for the HOOR derivatives ( $7^{\prime}$ in Fig. 1 ). These configurations are about $3 \mathrm{kcal} / \mathrm{mol}$ less stable than the ones shown in Fig. 1 as 7.

The HB distances are very dependent of the systems considered being the average one $1.94 \AA$ (Table II). In the case of the HOOR and $\mathrm{RCOOOH}$ the $\mathrm{HB}$ distance vary with the following order, $\mathrm{CH}_{3}<\mathrm{H}<\mathrm{CF}_{3}$. This result can be explained based on the effect of the $R$ groups in the availability 

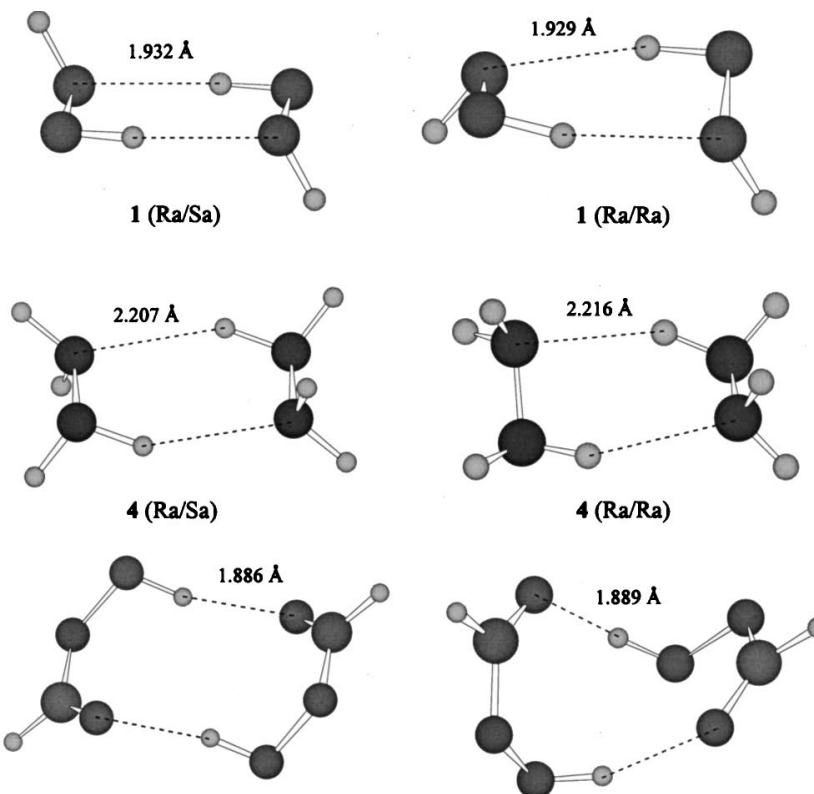

$7(\mathrm{Ra} / \mathrm{Sa})$

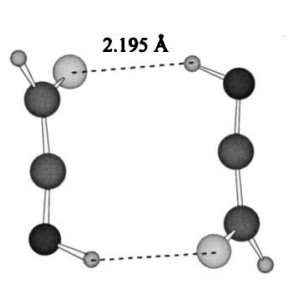

$12(\mathrm{Ra} / \mathrm{Sa})$
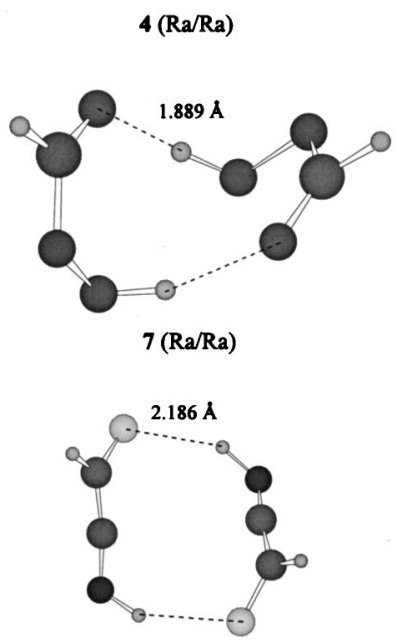

$12(\mathrm{Ra} / \mathrm{Ra})$

FIG. 2. Optimized structures of some of the complexes studied at the MP2/6-311++G** level.

of electrons by the HB acceptor. The angles are in general less linear than it is expected for this kind of HB due to the structural limitation of the monomers, reaching in some cases values of $140^{\circ}$.

The AIM analysis shows the presence of two bond critical points (bcp) between the atoms involved in the HB for all the complexes studied here (Table III). In addition, surprisingly, in the more compact complexes additional bcp are obtained between those $\mathrm{O} \cdots \mathrm{O}$ atoms pairs that are closer than $3.1 \AA$. This distance is similar to the one obtained in the van der Waals complex $\mathrm{H}_{2} \mathrm{CO} \cdots \mathrm{O} \equiv \mathrm{C}$ calculated at the MP2/6-31 $+\mathrm{G}^{* *}(3.147 \AA){ }^{20}$ In addition to a short distance between the atoms, a partial overlap of the lone pairs seems to be necessary for the appearance of a bcp. As an example, the electron density graph of the two dimers of $\mathbf{7}$ showing the bond paths and critical points have been included in Fig. 3 .

The presence of the mentioned bcp between oxygen atoms seems to provide an extra stabilization towards the ones without it. Thus, $\mathbf{3}$ is the only case in the HOOR series of compounds studied here where the homodimer is more stable than the heterodimer. In the family of the peracid derivatives, the one with the shorter $\mathrm{O} \cdots \mathrm{O}$ distance, which corresponds in all cases with the homochiral dimer, is the most stable. Bader has shown that the presence of a bond critical point and the corresponding bond path linking two nuclei provides additional stabilizing energy to the system independently of

TABLE II. Selection of the geometrical parameter $\left(\AA\right.$ and $\left.{ }^{\circ}\right) .{ }^{a}$

\begin{tabular}{|c|c|c|c|c|c|c|c|}
\hline \multirow[b]{2}{*}{ System } & \multirow[b]{2}{*}{ Chirality } & \multicolumn{2}{|c|}{ B3LYP/6-31+G** } & \multicolumn{2}{|c|}{ MP2/6-31+ G** } & \multicolumn{2}{|c|}{$\mathrm{MP} 2 / 6-311++\mathrm{G}^{* *}$} \\
\hline & & $\begin{array}{c}\mathrm{HB} \\
\text { distance }\end{array}$ & $\begin{array}{c}\text { HB } \\
\text { angle }\end{array}$ & $\begin{array}{c}\text { HB } \\
\text { distance }\end{array}$ & $\begin{array}{c}\mathrm{HB} \\
\text { angle }\end{array}$ & $\begin{array}{c}\mathrm{HB} \\
\text { distance }\end{array}$ & $\begin{array}{c}\mathrm{HB} \\
\text { angle }\end{array}$ \\
\hline 1 & $R_{a} / S_{a}$ & 1.923 & 155.2 & 1.940 & 156.1 & 1.932 & 154.5 \\
\hline 1 & $R_{a} / R_{a}$ & 1.920 & 154.4 & 1.942 & 155.6 & 1.929 & 153.6 \\
\hline 2 & $R_{a} / S_{a}$ & 1.903 & 156.7 & 1.884 & 157.6 & 1.877 & 156.4 \\
\hline 2 & $R_{a} / R_{a}$ & 1.905 & 156.8 & 1.891 & 158.1 & 1.888 & 155.6 \\
\hline 3 & $R_{a} / S_{a}$ & 2.117 & 145.4 & 2.081 & 144.9 & 2.071 & 144.5 \\
\hline 3 & $R_{a} / R_{a}$ & 2.077 & 144.2 & 2.081 & 141.9 & 2.063 & 141.6 \\
\hline 4 & $R_{a} / S_{a}$ & 2.218 & 150.1 & 2.208 & 149.9 & 2.207 & 149.6 \\
\hline 4 & $R_{a} / R_{a}$ & 2.227 & 150.3 & 2.219 & 150.9 & 2.216 & 150.5 \\
\hline 5 & $R_{a} / S_{a}$ & 2.213 & 153.2 & 2.152 & 154.5 & 2.150 & 154.3 \\
\hline 5 & $R_{a} / R_{a}$ & 2.224 & 153.5 & 2.151 & 154.2 & 2.148 & 153.8 \\
\hline 6 & $R_{a} / S_{a}$ & 2.286 & 146.3 & 2.178 & 146.0 & & \\
\hline 6 & $R_{a} / R_{a}$ & 2.283 & 148.2 & 2.171 & 148.2 & & \\
\hline 7 & $R_{a} / S_{a}$ & 1.832 & 156.3 & 1.887 & 154.7 & 1.886 & 159.7 \\
\hline 7 & $R_{a} / R_{a}$ & 1.796 & 169.0 & 1.862 & 160.5 & 1.889 & 154.0 \\
\hline 8 & $R_{a} / S_{a}$ & 1.844 & 146.8 & 1.904 & 143.2 & 1.905 & 143.5 \\
\hline 8 & $R_{a} / R_{a}$ & 1.771 & 1.712 & 1.834 & 160.9 & 1.829 & 160.4 \\
\hline 9 & $R_{a} / S_{a}$ & 1.932 & 139.8 & 1.980 & 137.4 & 1.989 & 137.3 \\
\hline 9 & $R_{a} / R_{a}$ & 1.824 & 166.1 & 1.913 & 152.7 & 1.909 & 152.0 \\
\hline 10 & $R_{a} / S_{a}$ & 1.709 & 163.5 & 1.783 & 153.9 & 1.785 & 154.8 \\
\hline 10 & $R_{a} / R_{a}$ & 1.681 & 172.8 & 1.734 & 167.6 & 1.736 & 166.6 \\
\hline 11 & $R_{a} / S_{a}$ & 1.920 & 167.0 & 1.894 & 168.2 & 1.913 & 167.2 \\
\hline 11 & $R_{a} / R_{a}$ & 1.905 & 175.5 & 1.908 & 175.7 & 1.920 & 176.8 \\
\hline 12 & $R_{a} / S_{a}$ & 2.275 & 143.7 & 2.178 & 142.8 & 2.195 & 142.6 \\
\hline 12 & $R_{a} / R_{a}$ & 2.294 & 146.1 & 2.189 & 146.5 & 2.186 & 149.1 \\
\hline
\end{tabular}

${ }^{\mathrm{a}}$ Due to symmetry reasons only one of the HB is indicated.

the nature of the atoms involved. ${ }^{21}$ In the same direction, a transition stated that presented an intermolecular noncovalent $\mathrm{O} \cdots \mathrm{O}$ bonding interaction in the hydrogen transfer assisted in the methoxy radical oxidation by $\mathrm{O}_{2}$ was considered to be stabilized by the mentioned contact. ${ }^{22}$

The NBO analysis (Table IV) of the complexes studied shows large energy interactions between the lone pair of the $\mathrm{HB}$ acceptor and the antibonding orbital of the $\mathrm{X}-\mathrm{H}$ moiety of the HB donor as have been described for other HBs. These orbital interactions are strongest in the more stable dimers with the exception of the dimers of $\mathbf{6}$. In addition, in the peracid derivatives small interactions between the hydroxy moiety of one monomer and the antibonding orbital of the same group in the opposite monomer have been found in those cases where the AIM methodology predicts the existence of a bcp between the oxygen atoms. At the same time those dimers without bcp in the AIM analysis does not show the mentioned additional interactions in the NBO analysis.

Finally, a correlation between the HB distance and the bcp and its laplacian has been attempted for the 14 dimers where $\mathrm{O} \cdots \mathrm{H}$ HBs are present. The results obtained (Fig. 4) indicate that the best fitting corresponds to an exponential relationship between the HB distance and the electron density parameters with very good correlation coefficients. 
TABLE III. Electron properties, electron density $\rho$, and Laplacian $\nabla^{2} \rho$ (a.u.) of the $\mathrm{HB}$ and additional intermolecular contacts calculated at the MP2/6-31+G** level.

\begin{tabular}{|c|c|c|c|c|c|c|c|}
\hline \multirow[b]{2}{*}{ System } & \multirow[b]{2}{*}{ Chirality } & \multicolumn{2}{|c|}{ HB } & \multicolumn{4}{|c|}{ Additional contacts } \\
\hline & & $\rho$ & $\nabla^{2} p$ & $\rho$ & $\nabla^{2} \rho$ & $\begin{array}{l}\text { Atoms } \\
\text { involved }\end{array}$ & Distance \\
\hline 1 & $R_{a} / S_{a}$ & 0.0260 & 0.0761 & & & & \\
\hline 1 & $R_{a} / R_{a}$ & 0.0254 & 0.0761 & & & & \\
\hline 2 & $R_{a} / S_{a}$ & 0.0301 & 0.0869 & & & & \\
\hline 2 & $R_{a} / R_{a}$ & 0.0292 & 0.0850 & & & & \\
\hline 3 & $R_{a} / S_{a}$ & 0.0193 & 0.0584 & & & & \\
\hline 3 & $R_{a} / R_{a}$ & 0.0185 & 0.0594 & $\begin{array}{l}0.0114 \\
0.0049\end{array}$ & $\begin{array}{l}0.0437 \\
0.0284\end{array}$ & $\begin{array}{l}\mathrm{O} \cdots \mathrm{O}^{\mathrm{a}} \\
\mathrm{F} \cdots \mathrm{F}\end{array}$ & $\begin{array}{l}2.90 \\
3.04\end{array}$ \\
\hline 4 & $R_{a} / S_{a}$ & 0.0188 & 0.0498 & & & & \\
\hline 4 & $R_{a} / R_{a}$ & 0.0183 & 0.0490 & & & & \\
\hline 5 & $R_{a} / S_{a}$ & 0.0215 & 0.0540 & & & & \\
\hline 5 & $R_{a} / R_{a}$ & 0.0216 & 0.0545 & & & & \\
\hline 6 & $R_{a} / S_{a}$ & 0.0200 & 0.0133 & & & & \\
\hline 6 & $R_{a} / R_{a}$ & 0.0210 & 0.0133 & & & & \\
\hline 7 & $R_{a} / S_{a}$ & 0.0251 & 0.0861 & & & & \\
\hline 7 & $R_{a} / R_{a}$ & 0.0291 & 0.0899 & 0.0100 & 0.0424 & $\mathrm{O} \cdots \mathrm{O}^{\mathrm{b}}$ & 2.95 \\
\hline 8 & $R_{a} / S_{a}$ & 0.0268 & 0.0846 & 0.0093 & 0.0380 & $\mathrm{O} \cdots \mathrm{O}^{\mathrm{b}}$ & 3.03 \\
\hline 8 & $R_{a} / R_{a}$ & 0.0311 & 0.0967 & 0.0106 & 0.0469 & $\mathrm{O} \cdots \mathrm{O}^{\mathrm{b}}$ & 2.94 \\
\hline 9 & $R_{a} / S_{a}$ & 0.0227 & 0.0728 & 0.0093 & 0.03488 & $\mathrm{O} \cdots \mathrm{O}^{\mathrm{b}}$ & 3.02 \\
\hline 9 & $R_{a} / R_{a}$ & 0.0261 & 0.0807 & 0.0096 & 0.0399 & $\mathrm{O} \cdots \mathrm{O}^{\mathrm{b}}$ & 2.94 \\
\hline 10 & $R_{a} / S_{a}$ & 0.0351 & 0.1106 & & & & \\
\hline 10 & $R_{a} / R_{a}$ & 0.0396 & 0.1221 & 0.0079 & 0.0322 & $\mathrm{O} \cdots \mathrm{O}^{\mathrm{b}}$ & 3.09 \\
\hline 11 & $R_{a} / S_{a}$ & 0.0233 & 0.0783 & 0.0034 & 0.0086 & $\mathrm{C} \cdots \mathrm{C}^{\mathrm{c}}$ & 3.96 \\
\hline 11 & $R_{a} / R_{a}$ & 0.0226 & 0.0748 & 0.0053 & 0.0138 & $C \cdots C^{c}$ & 3.45 \\
\hline 12 & $R_{a} / S_{a}$ & 0.0141 & 0.0516 & 0.0045 & 0.0138 & $C \cdots C^{c}$ & 3.42 \\
\hline 12 & $R_{a} / R_{a}$ & 0.0134 & 0.0494 & 0.0048 & 0.0146 & $C \cdots C^{c}$ & 3.37 \\
\hline
\end{tabular}

${ }^{a}$ Oxygens acting as a HB acceptor.

${ }^{\mathrm{b} H y d r o x y l}$ oxygen atoms.

${ }^{\mathrm{c}}$ Central carbon atoms of the allenes.

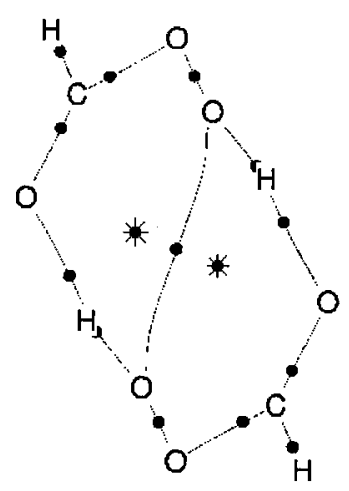

$7 R a / R a$

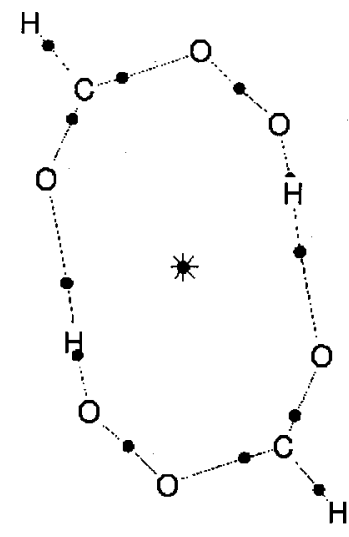

$7 R a / S a$
FIG. 3. Electron density graph of the dimers of 7 . The bcp are indicated by dots and the ring critical points by stars. The lines linking the atoms indicate the bond paths.
TABLE IV. NBO bonding-antibonding interactions ( $\mathrm{kcal} / \mathrm{mol})$ calculated at the $\mathrm{B} 3 \mathrm{LYP} / 6-31+\mathrm{G}^{* *}$

\begin{tabular}{|c|c|c|c|}
\hline System & Chirality & $\mathrm{LP} \cdots * \mathrm{BD}(\mathrm{H}-\mathrm{X})^{\mathrm{b}}$ & $\begin{array}{c}\text { Additional } \\
\text { orbital contacts }^{\mathrm{c}}\end{array}$ \\
\hline 1 & $R_{a} / S_{a}$ & 13.23 & \\
\hline 1 & $R_{a} / R_{a}$ & 12.83 & \\
\hline 2 & $R_{a} / S_{a}$ & 13.66 & \\
\hline 2 & $R_{a} / R_{a}$ & 13.49 & \\
\hline 3 & $R_{a} / S_{a}$ & 5.78 & \\
\hline 3 & $R_{a} / R_{a}$ & 6.25 & \\
\hline 4 & $R_{a} / S_{a}$ & 8.41 & \\
\hline 4 & $R_{a} / R_{a}$ & 8.24 & \\
\hline 5 & $R_{a} / S_{a}$ & 8.17 & \\
\hline 5 & $R_{a} / R_{a}$ & 8.07 & \\
\hline 6 & $R_{a} / S_{a}$ & 5.97 & \\
\hline 6 & $R_{a} / R_{a}$ & 6.23 & \\
\hline 7 & $R_{a} / S_{a}$ & 12.11 & \\
\hline 7 & $R_{a} / R_{a}$ & 20.56 & 0.80 \\
\hline 8 & $R_{a} / S_{a}$ & 12.69 & 0.58 \\
\hline 8 & $R_{a} / R_{a}$ & 22.34 & 1.44 \\
\hline 9 & $R_{a} / S_{a}$ & 9.47 & 0.84 \\
\hline 9 & $R_{a} / R_{a}$ & 18.83 & 1.00 \\
\hline 10 & $R_{a} / S_{a}$ & 20.57 & \\
\hline 10 & $R_{a} / R_{a}$ & 32.41 & 0.72 \\
\hline 11 & $R_{a} / S_{a}$ & 9.67 & \\
\hline 11 & $R_{a} / R_{a}$ & 10.65 & \\
\hline 12 & $R_{a} / S_{a}$ & 2.52 & \\
\hline 12 & $R_{a} / R_{a}$ & 2.38 & \\
\hline
\end{tabular}

${ }^{a}$ The atoms involved are the same in Table III.

${ }^{\mathrm{b}} \mathrm{LP}$ stands for lone pair.

${ }^{c} \mathrm{BD}$ stands for antibonding orbitals.

These results agree with recent reports on the relationships of these properties for a variety of bonds. ${ }^{23-26}$

\section{CONCLUSION}

A theoretical study of the relative stability of the dimerization due to HB formation of twelve compounds that present axial chirality using DFT and MP2 methods. In each cases, the corresponding homo- and heterochiral dimer has been considered. The electron density of the complexes has been analyzed using the AIM methodology and the orbital interaction with the NBO method.

The energetic results indicate no clear preferences for any of the two possible dimers, ranging the chirodiastaltic differences between $0.2-2.8 \mathrm{kcal} / \mathrm{mol}$. The electron density analysis shows that those complexes with additional intermolecular $\mathrm{O} \cdots \mathrm{O}$ interaction are more stable than those without them. The presence of these bcp is related to a short interatomic distance and to a partial overlap of the lone pairs of the atoms involved. In addition, the NBO analysis indicates small stabilizing orbital interactions in the additional intermolecular contact found in the AIM analysis. 

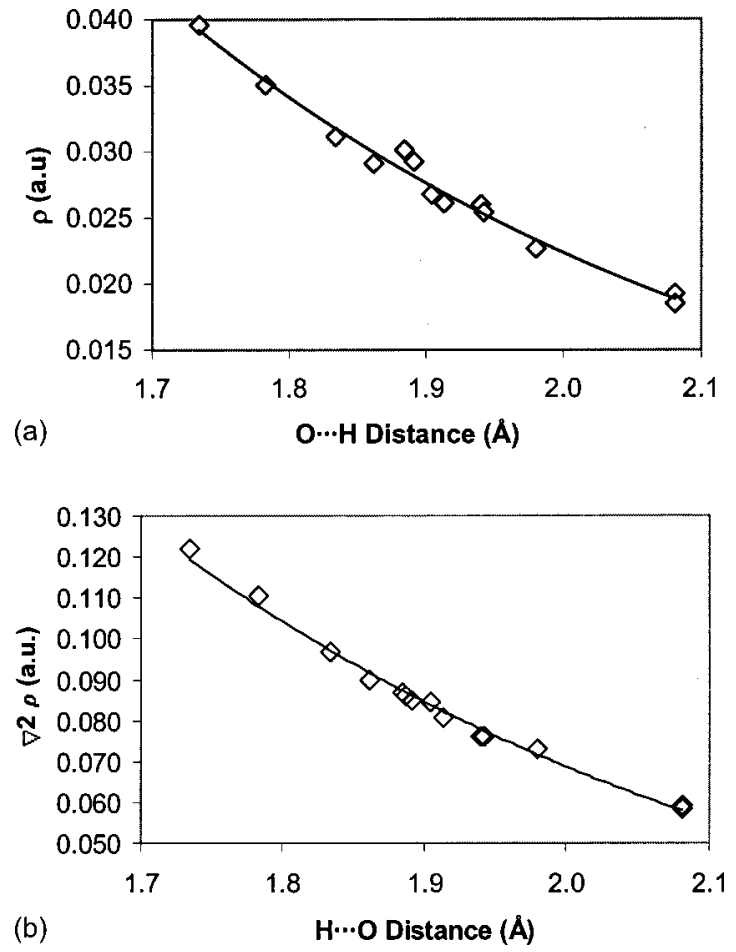

FIG. 4. Exponential relationship between the HB distance $d$ and (a) electron density at the bcp $\rho$ and (b) Laplacian of the electron density at the bcp $\nabla^{2} \rho$. The fitted curves are (a) $\rho=1.53 e^{-2.11 d}, R^{2}=0.98, n=14$; (b) $\nabla^{2} \rho=4.43 e^{-2.08 d}, R^{2}=0.99, n=14$.

\section{ACKNOWLEDGMENT}

This work was carried with financial support from the Ministerio de Ciencia y Tecnología (Project No. BQU-20000906).
${ }^{1}$ H. Wynberg and B. Feringa, Tetrahedron 32, 2831 (1976).

${ }^{2}$ D. P. Craig and D. P. Mellor, Top. Curr. Chem. 63, 1 (1976).

${ }^{3}$ S. Portmann, A. Inauen, H. P. Lüthi, and S. Leutwyler, J. Chem. Phys. 113, 9577 (2000)

${ }^{4}$ I. Alkorta and J. Elguero, J. Am. Chem. Soc. 124, 1488 (2002).

${ }^{5}$ A. D. McNaught and A. Wilkinson, Compendium of Chemical Terminology, The Gold Book, 2nd ed. (Blackwell Science, New York, 1997), http:// www.iupac.org/publications/books/author/menaught.html

${ }^{6}$ P. Holy, J. Závada, I. Císorová, and J. Pdlaha, Tetrahedron: Asymmetry 12, 3035 (2001)

${ }^{7}$ A. D. Becke, J. Chem. Phys. 98, 5648 (1993); C. Lee, W. Yang, and R. G. Parr, Phys. Rev. B, 37, 785 (1988).

${ }^{8}$ P. A. Hariharan and J. A. Pople, Theor. Chim. Acta 28, 213 (1973).

${ }^{9}$ Gaussian 98, M. J. Frisch, G. W. Trucks, H. B. Schlegel et al. Gaussian, Inc., Pittsburgh, PA, 1998.

${ }^{10}$ C. M $\phi 1 l e r$ and M. S. Plesset, Phys. Rev. 46, 618 (1934).

${ }^{11}$ S. B. Boys and F. Bernardi, Mol. Phys. 19, 553 (1970).

${ }^{12}$ R. F. W. Bader, Atoms in Molecules: A Quantum Theory (Oxford University Press, New York, 1990).

${ }^{13}$ F. W. Bieger-König, R. F. W. Bader, and T. H. J. Tang, J. Comput. Chem. 3, 317 (1982).

${ }^{14}$ F. Biegler-König, J. Schönbohm, and D. Bayles, J. Comput. Chem. 22, 545 (2001).

${ }^{15}$ A. E. Reed, L. A. Curtiss, and F. Weinhold, Chem. Rev. 88, 899 (1988).

${ }^{16}$ T. A. Beu and U. Buck, Z. Phys. Chem. (Munich) 214, 437 (2000).

${ }^{17}$ O. Mó, M. Yáñez, and J. Elguero, J. Chem. Phys. 100, 2871 (1994).

${ }^{18}$ A. Engdahl, B. Nelander, and G. Karlström, J. Phys. Chem. A 105, 8393 (2001).

${ }^{19}$ V. Dyczmons, J. Phys. Chem. A 104, 8263 (2000).

${ }^{20}$ The resulting complex with $C_{2 V}$ symmetry has been fully optimized, providing a total energy of -227.222204 hartrees at the MP2/6-31+ $\mathrm{G}^{* *}$ computational level which corresponds to a $E_{I}$ of $-0.28 \mathrm{kcal} / \mathrm{mol}$.

${ }^{21}$ R. W. F. Bader, J. Phys. Chem. A 102, 7314 (1998).

${ }^{22}$ J. M. Bofill, S. Olivella, A. Solé, and J. M. Anglada, J. Am. Chem. Soc. 121, 1337 (1999).

${ }^{23}$ I. Alkorta, I. Rozas, and J. Elguero, Struct. Chem. 9, 243 (1998); I. Alkorta, L. Barrios, I. Rozas, and J. Elguero, THEOCHEM 496, 131 (2000).

${ }^{24}$ E. Espinosa, M. Souhassou, H. Lachekar, and C. Lecomte, Acta Crystallogr., Sect. B: Struct. Sci. 55, 563 (1999).

${ }^{25}$ A. M. Pendas, A. Costales, and V. Luaña, J. Phys. Chem. B 102, 6937 (1998).

${ }^{26}$ E. Espinosa, I. Alkorta, J. Elguero, and E. Molins, J. Chem. Phys. 117, 5529 (2002) 